Tohoku J. Exp. Med., 1994, 174, 41-48

\title{
Late Results after Correction of Ventricular Septal Defect with Severe Pulmonary Hypertension
}

\author{
Kiyoshi Haneda, Naoshi Sato, Takao Togo, Makoto \\ Miura, Masaki Hata and Hitoshi Mohri \\ Department of Thoracic and Cardiovascular Surgery, \\ Tohoku University School of Medicine, Sendai 980-77
}

\begin{abstract}
Haneda, K., Sato, N., Togo, T., Miura, M., Hata, M. and Mohri, H. Late Results after Correction of Ventricular Septal Defect with Severe Pulmonary Hypertension. Tohoku J. Exp. Med., 1994, 174 (1), 41-48—- Fifty-eight patients with ventricular septal defect (VSD) associated with severe pulmonary hypertension $(\mathrm{Pp} / \mathrm{Ps} \geqq 0.90)$ were repaired between 1971 and 1992. Their preoperative $\mathrm{Pp} / \mathrm{Ps}, \mathrm{Rp} / \mathrm{Rs}$ and $\mathrm{Rp}$ were $0.98 \pm 0.06,2.37 \pm 1.20$ and $4.81 \pm 3.06$ units $\cdot \mathrm{m}^{2}$, respectively. Late results were analyzed in 56 operative survivors. The age at the time of operation ranged from 2 months to 32 years (average 4.1 years) and the postoperative follow-up period ranged from 1 month to 20 years (average 5.5 years). Eighty-two percent of the patients were in New York Heart Association functional class I, $15 \%$ were in class II and $3 \%$ in class III. The postoperative $\mathrm{Pp} / \mathrm{Ps}$ and $\mathrm{Rp} / \mathrm{Rs}$ significantly decreased to $0.41 \pm 0.13(p<0.001)$ and $0.25 \pm 0.16$ $(p<0.001)$, respectively. There were significant differences in $\mathrm{Rp} / \mathrm{Rs}$ and $\mathrm{Rp}$ between the patients operated on before (Group 1) and after 2 years of age (Group 2). $\mathrm{Rp} / \mathrm{Rs}$ and $\mathrm{Rp}$ in Group 1 were $0.17 \pm 0.06$ and $2.52 \pm 0.65$ units $\cdot \mathrm{m}^{2}$, whereas $0.31 \pm 0.19(p<0.05)$ and $4.26 \pm 1.88$ units $\cdot \mathrm{m}^{2}(p<0.05)$ in Group 2, respectively. One patient died 14 months after VSD closure due to respiratory failure. It is concluded that a patient with VSD associated with severe but reversible pulmonary hypertension should be surgically corrected before 2 years of age. ventricular septal defect; pulmonary hypertension; pulmonary vascular disease; oxygen inhalation test
\end{abstract}

Recent advances in operative techniques, and in pre- and postoperative patient management have allowed safe surgical closure of ventricular septal defect (VSD) with a low mortality rate. However, progress of pulmonary vascular disease (PVD) and late death due to PVD after correction of heart defects have been reported in patients with severe pulmonary hypertension (Allen et al. 1974; Friedli et al. 1974; Weidman and DuShane 1974; Moller et al. 1991). Therefore, this study was conducted to analyze the late results with respect to hemodynamics, physical activities, quality of school or social life and late mortality after correction of VSD with pulmonary hypertension equal to or greater than 0.9 of peak pulmonary to systemic arterial pressure ratio $(\mathrm{Pp} / \mathrm{Ps})$.

Received March 11, 1994; revision accepted for publication July 28, 1994. 


\section{Materials and Methods}

Fifty-eight patients with VSD and severe pulmonary hypertension $(\mathrm{Pp} / \mathrm{Ps} \geqq$ 0.9) underwent VSD closure in our institute between 1971 and 1992. Two patients died on 7th and 35th postoperative days due to low cardiac output syndrome and complete heart block, respectively. The 56 hospital survivors (29 males and 27 females) were followed for 1 month to 20 years (average 5.5 years) after correction of VSD. The age at the time of operation ranged from 2 months to 32 years with an average of 4.1 years. Thirty-three patients (58.9\%; Group 1) were less than 2 years of age and the remaining 23 patients (41.1\%; Group 2) were 2 years or more at the time of operation. Associated cardiovascular lesions were patent ductus arteriosus (PDA) in 12 patients, mitral regurgitation (MR) in 4, atrial septal defect (ASD) in 3, straddling the tricuspid valve in 2 and coronary arterial fistula in 1. There were 9 patients with Down's syndrome.

\section{Preoperative hemodynamics}

Average preoperative values of $\mathrm{Pp} / \mathrm{Ps}$, pulmonary to systemic blood flow ratio $(\mathrm{Qp} / \mathrm{Qs})$, pulmonary to systemic vascular resistance ratio $(\mathrm{Rp} / \mathrm{Rs})$ and pulmonary vascular resistance $(\mathrm{Rp})$ were $0.98,2.37,0.42$ and 4.81 units $\cdot \mathrm{m}^{2}$, respectively (Table 1 ). There were no significant differences in preoperative hemodynamic parameters between Groups 1 and 2. In the most recent 30 patients, the oxygen inhalation test was performed by administration of $100 \%$ of oxygen for 10 minutes with a face mask. $\mathrm{Pp} / \mathrm{Ps}$ significantly decreased from $0.97 \pm 0.05$ at room air to $0.85 \pm 0.11$ at $100 \%$ oxygen $(p<0.001), \mathrm{Rp} / \mathrm{Rs}$ from $0.44 \pm 0.23$ to $0.25 \pm 0.12(p<0.001)$ and $\mathrm{Rp}$ from $4.49 \pm 3.22$ to $2.70 \pm 1.30$ units $\mathrm{m}^{2}(p<0.01)$ (Fig. 1). Qp/Qs significantly increased with oxygen inhalation from $2.30 \pm 1.15$ to $3.36 \pm 1.89(p<0.005)$.

\section{Operation}

The VSD was closed with a patch under simple hypothermia (8 patients) or combined surface and perfusion hypothermia (10 patients) with total circulatory

TABLE 1. Preoperative hemodynamic variables

\begin{tabular}{cc}
\hline Variables & Values \\
\hline $\mathrm{Pp} / \mathrm{Ps}$ & $0.98 \pm 0.06$ \\
$\mathrm{Rp} / \mathrm{Rs}$ & $0.42 \pm 0.19$ \\
$\mathrm{Qp} / \mathrm{Qs}$ & $2.37 \pm 1.20$ \\
$\mathrm{Rp}\left(\right.$ units $\left.\cdot \mathrm{m}^{2}\right)$ & $4.81 \pm 3.06$ \\
\hline
\end{tabular}

$\mathrm{Pp} / \mathrm{ps}$, peak pulmonary to systemic arterial pressure ratio; Rp/Rs, pulmonary to systemic vascular resistance ratio; $\mathrm{Qp} / \mathrm{Qs}$, pulmonary to systemic blood flow ratio; Rp, pulmonary vascular resistance. Values are shown as mean \pm S.D. 

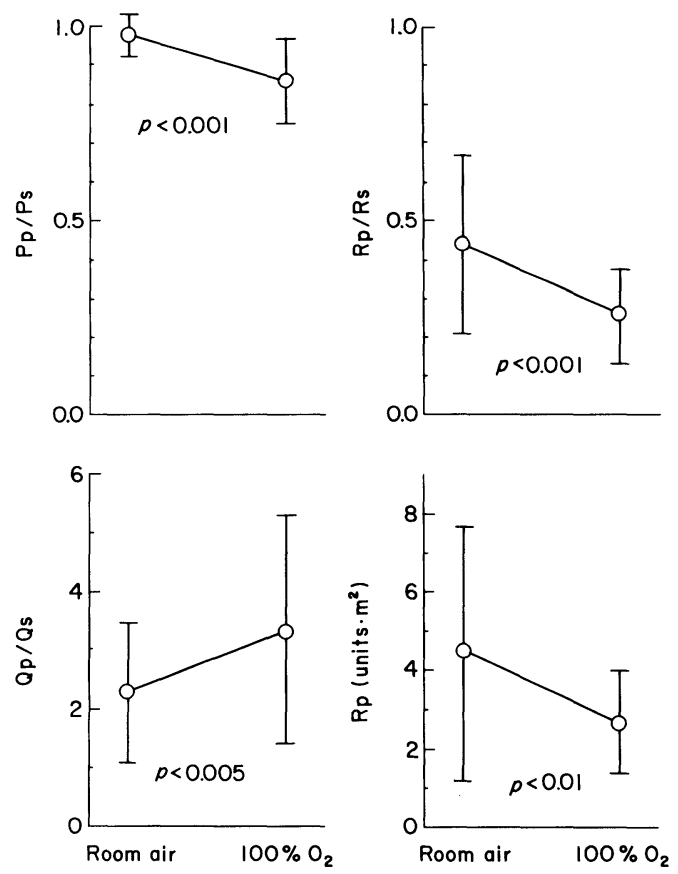

Fig. 1. Hemodynamic changes during oxygen inhalation test.

$\mathrm{Pp} / \mathrm{Ps}$, peak pulmonary to systemic arterial pressure ratio; $\mathrm{Rp} / \mathrm{Rs}$, pulmonary to systemic vascular resistance ratio; $Q p / Q s$, pulmonary to systemic vascular resistance ratio; $R p$, pulmonary vascular resistance. T-bars indicate S.D.

arrest, or under conventional cardiopulmonary bypass (38 patients). Associated PDA (12 patients) was ligated, ASD (3 patients) was suture closed and coronary arterial fistula (1 patient) was closed through an intracoronary arterial approach when the VSD was closed. One 26-year-old patient with severe MR underwent mitral valve replacement (MVR) with a $29 \mathrm{~mm}$ Carpentier-Edwards valve at the same time as VSD closure. In 11 patients, lung biopsy was performed during the operation.

\section{The follow-up studies}

Questionnaires were sent to the patients and information including subjective symptoms, cardiac medical care requirements, quality of school or social life, employment, marital status and progeny were collected. For patients who could not be directly contacted, this information was obtained from medical records. Twenty-five patients $(44.6 \%)$ were below 10 years of age, $17(30.4 \%)$ were between 10 and 19 years, and $14(25.0 \%)$ were 20 years or more at the time of this study.

\section{Statistical analysis}

Values are presented in terms of mean \pm s.D. Differences between pre- and 
postoperative values were analyzed by the paired $t$-test, and hemodynamic data between the patient groups were compared by the unpaired $t$-test and the $\chi^{2}$ test. The differences were considered to be statistically significant when a value was less than 0.05 .

\section{RESULTS}

\section{Functional status}

Current functional status was obtained in 34 patients. Twenty-eight patients $(82.4 \%$ ) were in New York Heart Association (NYHA) functional class I, 5 patients $(14.7 \%)$ were in class II and 1 patient $(2.9 \%)$ with postoperative severe MR was in class III. Sixteen school children or students replied to the questionnaires on school life. Twelve of them $(75 \%)$ described no physical exercise limitations and $4(25 \%)$ had mild to moderate limitations. Although exercise was limited in 2 patients with medical reasons (pacemaker implantation due to postoperative complete heart block in 1 and persistent pulmonary hypertension in 1), the remaining 2 patients had been placed in exercise limitations by school or family but not for medical reasons.

\section{Employment, marital status and progeny}

Nine non-student patients replied to the questionnaires on employment, marital status and progeny. Three males and 3 females were currently employed at the time of this study. There were 2 professional workers ( 1 computer programmer and 1 dental technician), 3 office workers and 1 sales worker. All of them were able to work as hard as their fellow workers. Two women were housewives. One patient (31-year-old man) with Down's syndrome was unemployed in spite of NYHA functional class I. Only 3 patients ( 1 male and 2 females) were married. Two of them have 3 children without the existence of known cardiovascular anomalies.

\section{Hemodynamic status}

Postoperative cardiac catheterization was performed in 26 patients (10 patients in Group 1 and 16 in Group 2) 1 month to 12 years (average 3.0 years) after the operation. The postoperative $\mathrm{Pp} / \mathrm{Ps}$ and $\mathrm{Rp} / \mathrm{Rs}$ significantly decreased from the preoperative values of $0.98 \pm 0.06$ to $0.41 \pm 0.13(p<0.001)$ and from $0.47 \pm 0.21$ to $0.25 \pm 0.16(p<0.001)$, respectively (Fig. 2$)$. In comparison of preand postoperative $R p$ values, the postoperative $R p$ also significantly decreased from the preoperative values of $6.19 \pm 3.96$ units $\cdot \mathrm{m}^{2}$ to $3.69 \pm 1.86$ units $\cdot \mathrm{m}^{2}(p<$ $0.05)$. Although the postoperative $\mathrm{Pp} / \mathrm{Ps}$ between these 2 groups did not show any significant differences, there were significant differences in the $\mathrm{Rp} / \mathrm{Rs}(0.17 \pm$ 0.06 in Group 1 vs $0.31 \pm 0.19$ in Group $2, p<0.05)$ and the $R p(2.52 \pm 0.65$ vs $4.26 \pm 1.88$ units $\cdot \mathrm{m}^{2}, p<0.05$ ) (Fig. 3). Furthermore, incidence of high values of postoperative $\mathrm{Pp} / \mathrm{Ps}, \mathrm{Rp} / \mathrm{Rs}$ and $\mathrm{Rp}$ indicating existence of $\mathrm{PVD}$ were 

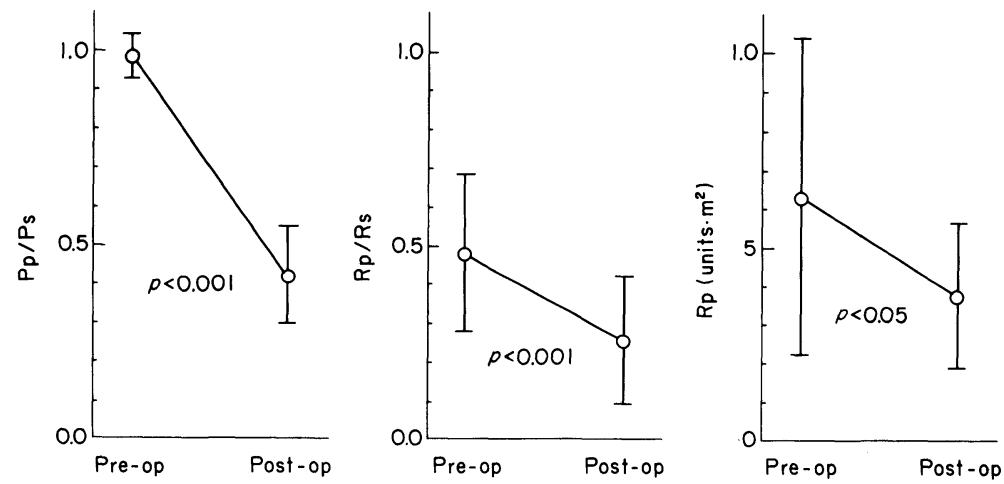

Fig. 2. Pre- and postoperative hemodynamic changes.

$\mathrm{Pp} / \mathrm{Ps}$, peak pulmonary to systemic arterial pressure ratio; $\mathrm{Rp} / \mathrm{Rs}$, pulmonary to systemic vascular resistance ratio; $\mathrm{Rp}$, pulmonary vascular resistance. T-bars indicate S.D.

significantly different between the 2 groups. In Group 1 , only 2 patients $(20.0 \%)$ showed postoperative pulmonary hypertension $\left(\mathrm{Pp} / \mathrm{Ps}_{0} \geqq 0.40\right)$, whereas 10 of the 16 patients $(62.5 \%)$ in Group 2 showed $\mathrm{Pp} / \mathrm{Ps} \geqq 0.40 \quad(p<0.05) \quad$ (Table 2). Although postoperative $\mathrm{Rp} / \mathrm{Rs}$ values equal to or greater than 0.30 were seen in $56.3 \%$ (9 patients) in the Group 2 patients, none of the patients in Group 1 showed the high $\mathrm{Rp} / \mathrm{Rs}$ values $(\geqq 0.30)(p<0.005)$. Postoperative $\mathrm{Rp}$ values were calculated in 17 patients (8 in Group 1 and 9 in Group 2). Five patients in Group 1 $(55.6 \%)$ showed $\mathrm{Rp}$ values equal to or greater than 4 units $\cdot \mathrm{m}^{2}$, whereas all patients in Group 1 had $\mathrm{Rp}$ values less than 4 units $\cdot \mathrm{m}^{2}(p<0.02)$. There were no patients who showed apparent evidence of progressive PVD in both of the 2 groups during the follow-up periods.
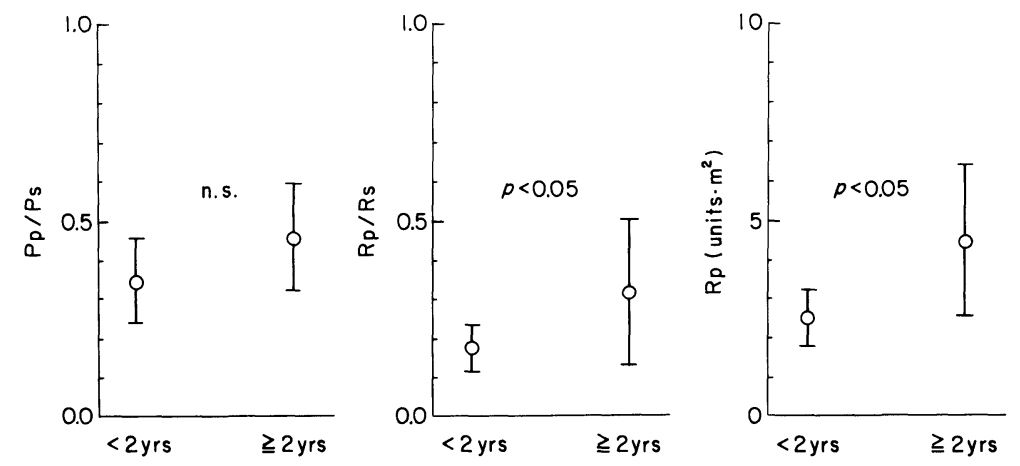

Fig. 3. Age at the operation and hemodynamic variables.

$\mathrm{Pp} / \mathrm{Ps}$, peak pulmonary to systemic arterial pressure ratio; $\mathrm{Rp} / \mathrm{Rs}$, pulmonary to systemic vascular resistance ratio; $R p$, pulmonary vascular resistance.

T-bar indicate S.D. 
TABLE 2. Age at the operation and hemodynamic variables

\begin{tabular}{cccc}
\hline Groups & $\mathrm{Pp} / \mathrm{Ps} \geqq 0.40$ & $\mathrm{Rp} / \mathrm{Rs} \geqq 0.30$ & $\mathrm{Rp} \geqq 4.0$ units $\cdot \mathrm{m}^{2}$ \\
\hline I & $2 / 10(20.0 \%)$ & $0 / 10(0 \%)$ & $0 / 8(0 \%)$ \\
II & $10 / 16(62.5 \%)$ & $9 / 16(56.3 \%)$ & $5 / 9(55.6 \%)$ \\
& $p<0.05$ & $p<0.005$ & $p<0.02$ \\
\hline
\end{tabular}

Group I: patients operated on before 2 years of age, Group II: patients operated on at or after 2 years of age. $\mathrm{Pp} / \mathrm{Ps}$, peak pulmonary to systemic arterial pressure ratio; $\mathrm{Rp} / \mathrm{Rs}$, pulmonary to systemic vascular resistance ratio; $\mathrm{Rp}$, pulmonary vascular resistance.

\section{Lung biopsy}

Lung biopsy was performed in 11 patients between 2 months and 2 years of age when the VSD was closed. PVD in the small pulmonary arteries was analyzed by both Heath-Edwards grading (Heath and Edwards 1958) and the Yamaki's IPVD score (Yamaki and Tezuka 1976). Heath-Edwards grade 1 PVD was seen in 2 patients, grade 2 was seen in 3 , grade 3 in 4 and grade 4 in 2 . On the other hand, the IPVD score in these patients ranged from 1.2 to 2.2 (average 1.6). There was a significant linear correlation between IPVD and preoperative $\operatorname{Rp}(\mathrm{r}=0.74, p<0.02)$ (Fig. 4).

\section{Reoperation}

Four patients required reoperation. Closure of residual VSD was performed in 2 patients 1 month and 1 year after the initial operation, respectively. Pulmonary valve replacement with a $29 \mathrm{~mm}$ of Björk-Shiley valve was performed in 1 patient due to severe pulmonary regurgitation 8 years after VSD closure. The

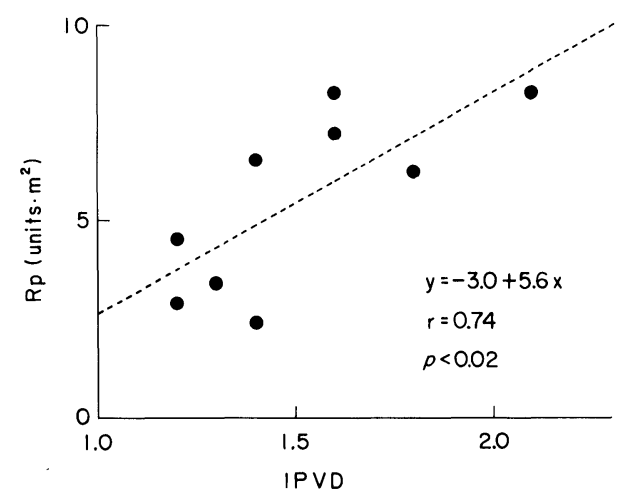

Fig. 4. Correlation between Rp and IPVD.

$\mathrm{Rp}$, pulmonary vascular resistance; IPVD, index of pulmonary vascular disease. 
remaining 1 patient, in whom MVR had been performed at the same time as VSD closure, required re-MVR due to malfunctioning the bioprosthetic valve 14 years postoperatively.

\section{Late deaths}

One patient died at the age of 17 months due to respiratory failure 14 months after VSD closure although $\mathrm{Pp} / \mathrm{Ps}$ decreased to 0.48 immediately after the operation.

\section{Discussion}

The pulmonary vasculature is a dynamic system and is subject to many mechanical, neural and chemical influences. Therefore, several methods to relieve pulmonary vasoconstriction have been utilized in order to assess the reversibility of pulmonary hypertension. Although pulmonary vasculature can be dilated with administration of oxygen and of pharmacological agents such as tolazoline, acetylcholine, prostaglandins etc., the value of the oxygen inhalation test (Burchell et al. 1953) is substantial among these tests from the practical point of view. The oxygen inhalation test has been used to determine the operability of patients with severe pulmonary hypertension in our institute. The 26 patients in this study showed good hemodynamic response to oxygen inhalation. They were judged that the pulmonary vascular changes were reversible. The postoperative pulmonary artery pressure in these patients significantly decreased and proved the feasibility of this test for determination of the operative indication.

Although the Heath-Edwards (Heath and Edwards 1958) classification has been widely utilized as a histopathological method to evaluate the PVD, it can provide only qualitative information about plexogenic pulmonary arteriopathy. On the other hand, the IPVD method (Yamaki and Tezuka 1976) is designed to allow for an overall evaluation of the plexogenic vascular lesions of all small pulmonary arteries observed in histological sections and has been utilized to assess PVD in our institute. Using this IPVD method, Yamaki et al. (1987) has reported that an IPVD rating of 2.2 in Down's syndrome and 2.1 without the syndrome are regarded as the upper possible limits for VSD closure.

There have been several reports of late deaths due to postoperative progress of PVD (Allen et al. 1974; Friedli et al. 1974; Weidman and DuShane 1974; Moller et al. 1991). Because PVD is a progressive disease, surgical correction of VSD should be done while PVD is reversible. In this study, no patients showed any evidences of progressive PVD. However, the patients who underwent VSD closure after the age of 2 developed significantly higher postoperative $\mathrm{Rp} / \mathrm{Rs}$ and $\mathrm{Rp}$ compared to the patients operated on before 2 years of age, as has been reported by others (Friedli et al. 1974; Weidman and DuShane 1974).

Most of the patients in this study were in NYHA functional class I without limitation in physical activities. It has been reported, however, that higher late 
mortality rates after closure of VSD were observed in patients operated on after the age of 5 and with a pre-or postoperative pulmonary vascular resistance greater than 7 units $\cdot \mathrm{m}^{2}$. However, late deaths in these patients occured due to not only PVD but all causes (Moller et al. 1991). Therefore, it is concluded that a patient with VSD associated with severe but reversible pulmonary hypertension should be surgically corrected before 2 years of age.

\section{References}

1) Allen, H.D., Anderson, R.C., Noren, G.R. \& Moller, J.H. (1974) Postoperative follow-up of patients with ventricular septal defect. Circulation, 50, 465-471.

2) Burchell, H.B., Swan, H.J.C. \& Wood, E.H. (1953) Demonstration of differential effects on pulmonary and systemic arterial pressure by variation in oxygen content of inspired air inpatients with patent ductus arteriosus and pulmonary hypertension. Circulation, 8, 681-694.

3) Friedli, B., Kidd, B.S.L., Mustard, W.T. \& Keith, J.D. (1974) Ventricular septal defect with increased pulmonary vascular resistance. Late results of surgical closure. Am. J. Cardiol., 33, 403-409.

4) Heath, D. \& Edwards, J.E. (1958) The pathology of hypertensive pulmonary vascular disease. A description of six grades of structural changes in the pulmonary arteries with special reference to congenital cardiac septal defects. Circulation, 18, 533-547.

5) Moller, J.H., Patton, C., Varco, R.L. \& Lillehei, C.W. (1991) Late results (30 to 35 years) after operative closure of isolated ventricular septal defect from 1954 to 1960. Am. J. Cardiol., 68, 1491-1497.

6) Yamaki, S. \& Tezuka, F. (1976) Quantitative analysis of pulmonary vascular disease in complete transposition of the great arteries. Circulation, 54, 805-809.

7) Yamaki, S., Haneda, K., Yaginuma, G., Akimoto, H., Akino, Y., Ito, T., Suzuki, Y., Ishizawa, E., Horiuchi, T. \& Ogata, H. (1987) Lung biopsy diagnosis of operative indication in ventricular septal defect and/or patent ductus arteriosus with severe pulmonary hypertension. J. Jpn. Assoc. Thorac. Surg., 35, 2143-2151,

8) Weidman, W.H. \& DuShane, J.W. (1974) Course of pulmonary hypertension following surgical closure of ventricular septal defect. Adv. Cardiol., 11, 131-134. 